\title{
ABDOURAHMAN A. WABERI, Pourquoi tu danses quand tu marches
}

\section{Alba Pessini}

\section{OpenEdition}

\section{Journals}

\section{Édition électronique}

URL : https://journals.openedition.org/studifrancesi/32368

DOI : $10.4000 /$ studifrancesi.32368

ISSN : 2427-5856

\section{Éditeur}

Rosenberg \& Sellier

\section{Édition imprimée}

Date de publication : 1 août 2020

Pagination : 449-450

ISSN : 0039-2944

\section{Référence électronique}

Alba Pessini, « abdourahman a. waberi, Pourquoi tu danses quand tu marches », Studi Francesi [En ligne], 191 (LXIV | II) | 2020, mis en ligne le 01 septembre 2020, consulté le 18 septembre 2021. URL : http:// journals.openedition.org/studifrancesi/32368; DOI : https://doi.org/10.4000/studifrancesi.32368

Ce document a été généré automatiquement le 18 septembre 2021.

\section{$\circledast \oplus \Theta \Theta$}

Studi Francesi è distribuita con Licenza Creative Commons Attribuzione - Non commerciale - Non opere derivate 4.0 Internazionale. 


\title{
ABDOURAHMAN A. WABERI, Pourquoi tu danses quand tu marches
}

\author{
Alba Pessini
}

\section{RÉFÉRENCE}

ABDOURAHMAN A. WABERI, Pourquoi tu danses quand tu marches, Paris, JC Lattès, 2019, 249 pp.

1 Le flux de souvenirs qui noircit les pages de ce roman est sollicité par la question apparemment anodine que Béa, une enfant de cinq ans adresse à Aden, son père, un matin alors qu'il la conduit à l'école, à la lisière du $\mathrm{X}^{\mathrm{e}}$ et $\mathrm{du} \mathrm{IX}^{\mathrm{e}}$ arrondissements de Paris: «Papa, pourquoi tu danses quand tu marches?». L'adulte pris de cours ne peut pourtant s'y soustraire et décide de retracer pour Béa (mais aussi pour lui) le chemin de son enfance qu'il avait relégué aux oubliettes: «Je vais te raconter le pays de mon enfance. Et tu les auras toutes les histoires qui ont marqué mes jeunes années. [...] Je te parlerai du désert mouvant autour de Djibouti, ma ville natale. Je te parlerai de la mer Rouge. Je te parlerai de mon quartier et de ses maisonnettes au toit en tôle d'aluminium» (p. 32). C'est ainsi qu'Aden part à la recherche de l'enfant qu'il a été, un enfant différent des autres, chétif, en demande d'attentions (trop peut-être?) qu'il ne reçoit guère. Un freluquet mal aimé par sa mère Zahra «revêche et distante» (p. 122) qui, quand il pleure, le confie à une autre femme comme «un colis encombrant», peu considéré par son père, Amine la Tige, raillé par ses camarades de classe dont il subit les quolibets. Tout le prédispose à une enfance solitaire, à l'écart; la poliomyélite qu'il contracte à sept ans marque définitivement son destin d'exclu et lui confère une démarche à jamais chaloupée. Seule la grand-mère, Nadifa, qu'Aden surnomme Cochise, «en hommage à un célèbre chef indien» (p. 17) semble s'intéresser à lui, lui redonnant confiance: «Oui c'est bien Cochise qui, la première, m'a enseigné à ne pas me considérer comme un infirme» (p. 214). C'est elle qui apaise ses pleurs et ses souffrances sans faire preuve à son égard d'une tendresse excessive; Cochise a cependant cet instinct maternel qui fait défaut à Zahra. L'arrivée de la jeune bonne Ladane de dix-sept ans dans la famille coïncide avec les premiers émois et le réveil de la sensualité qui 
troublent l'enfant; elle est «la fleur de lotus qui trônait dans la boue de mon quartier» (p. 144). À travers ces souvenirs, c'est également une partie de l'histoire de la dernière colonie française nommée à l'époque «Territoire français des Afars et des Issas» qui nous est livrée par bribes, par touches, selon la nécessité de la narration.

Le récit de ces années d'enfance et d'adolescence est ponctué de moments pénibles et douloureux: l'arrivée de son frère cadet, «un amour de bambin et tout mon contraire» (p. 104), va lui ravir le peu d'attachement que ses parents avaient pour lui, la circoncision qu'il affronte tout seul s'avère une circonstance terrible que l'enfant n'est pas près d'oublier, les harcèlements verbaux et physiques des autres gamins du quartier l'isolent d'un monde auquel il ne peut prendre part. Un vieux chien sans nom, sale, au pelage rebutant s'avère être le seul dans le quartier à l'accepter, partageant les mêmes déboires que lui: «Le vieux cabot et moi formions un couple. Un couple d'éclopés mais un couple quand même. [...] Nous vivions au milieu de ce quartier bruyant où personne ne prêtait attention à nous. Pire, nous étions tenus à distance comme des lépreux» (pp. 172-173).

3 L'école est pour Aden un lieu refuge, un véritable sanctuaire où il se sent préservé de toute attaque et surtout il y retrouve Madame Annick, son institutrice, une française de France à laquelle il dévoue une admiration sans borne: «Pour un sourire de Madame Annick j'étais prêt à tout» (p. 48). Madame Ellul, sa professeure de français au collège, lui accorde l'attention tant recherchée, elle lit sa première rédaction à haute voix et concourt à faire du jeune garçon une célébrité de tout l'établissement. Au lycée, il rejoint le Club de lecture et l'équipe du journal et acquiert une indispensable assurance grâce aux enseignants parmi lesquels il trouve d'indéfectibles alliés. C'est à l'école que l'enfant développe un goût immodéré pour la lecture: «J'étais toujours à l'affût de quelque livre ou magazine à dévorer» (p. 92), il lit tout ce qui lui tombe sous la main et est disposé à mettre sa jambe malade à dure épreuve et à s'aventurer au-delà de son quartier pour un butin somme toute dérisoire: roman-photo, bandes dessinées à moitié déchirées, Paris Match en mauvais état et bien plus rarement un livre. Le malaise que l'enfant éprouve dans sa famille, cette appétence pour la lecture vont le projeter vers un ailleurs qu'il ne saisit pas encore mais qu'il envisage comme une rupture avec ce qu'il a connu jusqu'alors: «J'échafaudais des plans dans ma tête, Béa: courir pour attraper ce monde qui m'échappait. Quitter à jamais ce monde étriqué» (p. 135).

Tout en livrant le récit de son enfance à Béa, le narrateur-conteur (digne petit-fils d'une grand-mère qui l'a bercé de ses histoires qu'il remémore comme les moments les plus précieux) affronte ses démons, les non-dits, les souffrances, les culpabilités qu'il a portés en lui et dont il se libère en les nommant. Voilà le moment venu de la résilience à laquelle il accède à travers la lecture et l'écriture. Cette dernière devient son arme, lors de son passage au lycée, de défense contre les «caïds» comme il les appelle, qui recourent à ses services pour leurs rédactions: «C'était à moi de leur ôter cette épine du pied. En échange, ils me promettaient de veiller sur ma sécurité cette année scolaire et la suivante» (p. 198).

5 Le départ rêvé s'effectue pour Aden à un moment bien précis qui correspond à la mort de Cochise et à sa réussite au bac; rien ne semble plus le retenir: «Et je suis parti en abandonnant tous les souvenirs de mon quartier. J'étais égoïste. Je voulais sauver ma peau. J'ai tout laissé derrière moi, Béa» (p. 222). L'arrivée en France est un moment difficile, cependant les dernières pages de l'œuvre s'attardent sur l'homme que le petit 
Aden est devenu, comblé, heureux, un homme qui danse non pas parce qu'il boite mais parce qu'il a finalement vaincu ses démons et épousé le rythme de l'existence.

6 Ce n'est qu'à peine camouflé derrière le genre de l'autofiction qu'Abdourahman A.Waberi nous livre ce qu'il nomme «la vérité des émotions» dans un texte hybride qui alterne la prose et des passages plus poétiques où le narrateur/conteur tente à la fois de surmonter les désagréments de sa condition et de s'offrir une échappatoire dans la seule voie qui lui parait praticable: celle de devenir écrivain. 